\title{
Liberalismo, sanción y reproche en Motivos reprochables, de J. M. Peralta [2012, Marcial Pons, Madrid, 341 págs.]
}

\author{
Matías Parmigiani*
}

\begin{abstract}
"Es evidente que cuando alabamos una acción nos cuidamos solamente de los motivos que la produjeron, y consideramos esa acción como signo o indicación de ciertos principios de la mente y el carácter". David Hume, Tratado de la naturaleza humana, pág. 643.
\end{abstract}

Recepción: 01/07/13.

Revisiones: 18/2/2015.

Aceptación: 13/5/15.

Resumen: En el presente trabajo, Parmigiani intentará argüir que la cita a Ferrajoli no solo no es necesaria para dotar de sustento a la argumentación de Peralta -ella sería independiente de lo que dice Ferrajoli- sino que ni siquiera resultaría útil en tanto criterio evaluativo tendiente a poner a prueba cualquier teoría penal que se precie de auténticamente liberal.

Palabras clave: derecho penal, motivación, penas.

Abstract: In the present work, Parmigiani will try to argue that the appointment to Ferrajoli not only is not necessary to provide sustenance to Peralta's argumentation -it would be independent from what Ferrajoli says - but that it would not even turn out to be useful as evaluative criterion tending to test any penal theory that boasts of authentic liberal.

Key words: criminal law, motivation punishment.

* Universidad de Girona, CONICET. Email: matiasparmigiani@gmail.com. 
Matías Parmigiani

\section{Introducción: ¿un buen comienzo?}

Motivos reprochables, el admirable libro de José M. Peralta que Marcial Pons editara en el 2012, abre con el siguiente epígrafe extraído de Derecho y razón de Luigi Ferrajoli: "Y el ciudadano, si bien tiene el deber jurídico de no cometer hechos delictivos, tiene el derecho de ser interiormente malvado y de seguir siendo lo que es"1. Que el libro no solo comience sino que culmine con esta cita ${ }^{2}$ no obedece a una mera casualidad. El propósito central que impulsa a Peralta consiste en determinar cuán compatible resulta un derecho penal liberal con una legislación que grava las penas en virtud de los motivos que pudieron impulsar la comisión de cierto tipo de delitos. En este sentido, la cita de Ferrajoli parece la inspiración perfecta para ensayar una respuesta negativa, pergeñada con el fin de mantener a raya a un Estado con la probada capacidad de extralimitarse y realizar ciertas intromisiones.

No obstante, al menos por dos razones, la cita de Ferrajoli resulta problemática. Lo primero que llama la atención es una suerte de presupuesto en ella encerrado. Al dividir tajantemente la vida humana en una parte interior (digamos, las afecciones, las motivaciones, los sentimientos y las disposiciones del carácter) y otra exterior (básicamente, las acciones), pareciera sugerir que nada que sea exclusivamente localizable en la interioridad del individuo puede ser objeto de intromisión jurídica. Al corresponder esta interioridad a lo que sucede en la esfera privada del individuo y al no perjudicar a terceros, la cita no parece más que una paráfrasis del principio de daño postulado por J. S. Mill ${ }^{3}$. El detalle es que para que algo evite causar daño a terceros no es necesario que sea relativo al mundo interior que habita una persona; con tal de que sean autorreferenciales, una cantidad nada despreciable de

1 Ferrajoli, L., Derecho y razón. Teoría del garantismo penal, Madrid, Trotta, 2001, pág. 223.

2 Peralta, J. M., Motivos reprochables. Una investigación acerca de la relevancia de las motivaciones individuales para el Derecho penal liberal, Madrid, Marcial Pons, 2012, pág. 312.

3 Mill, J.S., Ensayo sobre la libertad, traducción de M. A. Lavilla Navarro, Mestas Ediciones, Madrid, cap. IV, 2006. 
acciones humanas -por definición, localizables en el mundo exteriorse verán preservadas de la intromisión que Ferrajoli juzga indeseable.

Dicho esto, lo segundo que llama la atención es la irrelevancia que adquiere la tarea de delimitar lo que pertenece a la vida interior de la exterior de los seres humanos para fijar el área de intromisión legítima de un Estado. Pues, volviendo a emplear el tropo sintáctico de Ferrajoli, con tal de que se abstenga de delinquir, uno también puede adjudicarle al ciudadano el derecho de ser exteriormente malvado y de seguir siendo lo que es. Para el Derecho, el único asunto importante será el de dónde fijar el umbral que ha de permitir circunscribir, en primera instancia, de todo el universo comprendido por las acciones externas, aquella porción específica en la que se constata la producción de un daño; y, en segunda instancia, dentro de esta porción, aquella subsección en la que se constataría la producción de un daño que no resulte moral sino jurídicamente relevante regular a efectos prácticos ${ }^{4}$.

Por estas y otras razones, en el presente trabajo intentará argüirse que semejante apoyo autoritativo no solo no es necesario para dotar de sustento a la argumentación de Peralta -según se sugerirá en unos instantes, ella sería independiente de lo que dice Ferrajoli- sino que ni siquiera resultaría útil en tanto criterio evaluativo tendiente a poner a prueba cualquier teoría penal que se precie de auténticamente liberal.

\section{II.Reconstruyendo la tesis de Peralta}

El texto de Peralta presenta dos estrategias argumentativas claramente diferenciadas. La primera de ellas (cf. partes I y II) se apoyaría en una concepción del liberalismo no necesariamente reducible a la estrecha concepción de Ferrajoli. Viene a decir, puesto brevemente,

4 Tratándose del Derecho civil, bastaría con tomar en cuenta estas dos instancias. Tratándose del Derecho penal, en cambio, habría que añadir una tercera. Definida aquella subsección en la que se constataría la producción de un daño que resulte jurídicamente relevante regular a efectos prácticos, dentro de ella habría que definir, a su vez, un área de acciones para las que la mera regulación civil se considere insuficiente. Recién aquí ingresaríamos en el terreno propiamente penal. 
Matías Parmigiani

que en tanto la práctica de agravar las penas en virtud de las motivaciones reprochables comporte una transgresión al principio de legalidad que tan distintivamente caracteriza al Estado liberal de Derecho, esta práctica debería merecer nuestro más enérgico rechazo. Peralta pone al descubierto cómo se transgrede el principio de legalidad, por ejemplo, cuando analiza la relevancia de las motivaciones reprochables desde el punto de vista de una teoría preventiva especial de la pena, particularmente cuando sostiene que dejar en manos del juez una discrecionalidad amplia para decidir qué motivaciones agravarían una pena traería consigo la "pérdida de la previsibilidad y la seguridad jurídica que están detrás del principio de legalidad"5. Más adelante vuelve a hacer lo propio cuando se pronuncia sobre el modelo preventivo general, al que le imputa violar "la autonomía de las personas en el siguiente sentido: no se puede hacer un cálculo de las consecuencias del acto". En efecto, si las necesidades de la pena se determinan ex post $\mathrm{y}$, por ende, "no pueden ser calculadas por el autor", una pena que se agrave ex post a tenor de las motivaciones que puedan haberlo impulsado a delinquir no le permitirán a este averiguar con precisión a qué atenerse ${ }^{6}$.

En cuanto a la segunda estrategia, Peralta parte de "la hipótesis de que es posible explicar y justificar la relevancia de los motivos para el Derecho penal de modo compatible con las restricciones" y de las premisas de un Estado liberal y un Derecho penal de acto ${ }^{7}$. Para ello, desarrolla una teoría capaz de "dar cuenta de la variación de la pena basada en los motivos aun sin apartarse de una estructura de análisis exclusivamente dogmática y, en este sentido, liberal"8. Una tesis de Müssig le sirve de fuente inspiradora. De tal manera, así como para

5 Peralta, J. M., Motivos reprochables. Una investigación acerca de la relevancia de las motivaciones individuales para el Derecho penal liberal, Madrid, Marcial Pons, 2012, pág. 57.

6 Ibidem, pág. 133.

7 Peralta, J. M., Motivos reprochables. Una investigación acerca de la relevancia de las motivaciones individuales para el Derecho penal liberal, Madrid, Marcial Pons, 2012, pág. 24.

8 Ibídem, pág. 25. 
este autor era posible dar cuenta de la diferencia de pena entre el homicidio y el asesinato una vez que llegamos a advertir que, en el primero, "el acontecimiento delictivo puede serle atribuido en parte a la víctima porque ella, con su conducta previa, lo ha motivado de algún modo", para Peralta, "cuando el autor obra por motivos reprochables, o bien la víctima no ha hecho nada en sentido empírico para desencadenar el acontecimiento o lo que ha hecho constituye el ejercicio de un derecho".

La intuición que ha tenido Peralta para llegar a esta formulación es de una hondura digna de destacarse. A fin de plasmarla, se esfuerza por vincular "el concepto de motivos con otras instituciones del Derecho penal donde las razones también juegan un rol decisivo: las causas de justificación en sentido amplio"10. Ello le permite tres cosas: "en primer lugar, desarrollar una teoría más abarcadora de la relevancia de los motivos que la haga extensible a otras circunstancias que reducen el ilícito, como por ejemplo el consentimiento o el estado de necesidad"; en segundo lugar, "dar cuenta, bajo la idea de reducción parcial del ilícito, de los motivos que fundamentan el injusto", "cuestión que -como él mismo aclara- no se encuentra vinculada, por regla general, a la conducta de la víctima"; y, finalmente, explicar "el camino que vincula (de modo en un principio sorprendente) circunstancias, como las causas de justificación, con algo aparentemente subjetivo como los motivos reprochables"11.

Por un lado, sabemos qué impulsa a Peralta a emprender esta cruzada. Como ya ha sido dicho, es aquella intuición de Ferrajoli de que todos tendríamos un derecho a ser interiormente tan malvados como deseemos. En el viejo enfoque dogmático, las motivaciones subjetivas agravaban la pena y esto era incompatible con un derecho penal de acto. Ahora bien, si en lugar de entender las motivaciones reprochables del Derecho penal como estados internos de las personas, las interpretamos como una manera de referirnos a todo aquello que no es

9 Ibídem, pág. 311.

${ }^{10}$ Ibídem, pág. 311.

${ }^{11}$ Ibidem, págs. 311-312. 
Matías Parmigiani

susceptible de justificación, la intuición de Ferrajoli parece salvaguardarse al mismo tiempo que se dota a la dogmática jurídica de la posibilidad de determinar cómo actuar ante un caso de 'motivación reprochable' sin apartarse del espíritu de la ley.

En realidad, la vuelta de tuerca que encuentra Peralta no habría sido posible si antes no hubiera advertido la incorrección fatal encerrada en la idea que afirma "la supuesta independencia entre motivo y hecho", es decir, la idea de que "los motivos sean algo que se suma al hecho típico, antijurídico y culpable y que no forma parte alguna de estas tres categorías"12. Peralta pone al descubierto la manifiesta problematicidad de esta idea a lo largo de la 'Primera Parte' de su trabajo, abocada a criticar el modo como desde las distintas teorías de la pena (pero en especial las utilitaristas) pretendió dársele cauce a la posibilidad de agravar las penas en función de la reprochabilidad de los motivos. ¿Y cuál era el problema central? En esencia, que "si la pena se puede agravar gracias a la introducción, como criterio de medición, de factores no vinculados al hecho en sí", como la supuesta peligrosidad del autor o el grado de irritación social que ciertos motivos generan, nada podría impedir en principio la instrumentalización de ciertos individuos para la prosecución de fines proteccionistas y la consiguiente violación del principio de legalidad.

Contra esta idea, Peralta defiende la hipótesis de que los motivos forman parte del hecho, al hallarse "reflejados" en el acontecimiento externo que permite determinar el grado de antijuridicidad de la acción ${ }^{13}$, así como la gravedad del tipo y la culpabilidad. He aquí, pues, uno al lado del otro, los elementos centrales de la teoría del delito. Cuando estos elementos son empleados por la dogmática jurídica de corte liberal, ellos sirven principalmente al objeto de fijar las garantías de que dispone el individuo frente al poder del Estado. Así, solo por tomar el caso más representativo, esto es lo que ni más ni menos ha acontecido, constata Peralta, "bajo el rótulo general del "límite de la culpabilidad" con el que se ha intentado demarcar "hasta 
dónde el castigo puede ser considerado legítimo" y de qué manera "la culpabilidad debe funcionar o hacer las veces de límite máximo de la responsabilidad penal". Sin embargo, como queda en evidencia a lo largo de la 'Segunda Parte' del libro, no es en ninguna de las principales variantes de la teoría del delito en donde Peralta encuentra la solución tendiente a determinar qué hacer con los motivos. Por lo pronto, porque si volvemos a tomar como ejemplo paradigmático el caso de la culpabilidad -y algo similar podría decirse de la antijuridicidad y del tipo-, lo único que ella le permitirá al juez es realizar una consideración de los motivos que cumplan una función exactamente "opuesta a la sindicada por los ordenamientos jurídicos", i.e. la de "agravar la situación del autor" (pág. 193). Dicho de modo alternativo, desde este concepto liberal de culpabilidad, "los motivos efectivamente pueden tener relevancia", pero "solo en la medida en que puedan significar una disminución" de la misma, o, como dice Paeffgen, "cuando tienen una fuerza tal que dificultan la capacidad de control del sujeto" (pág. 194) ${ }^{14}$.

¿Cómo hacer entonces para que la dogmática se mantenga dentro de los márgenes sin que esto implique rechazar el ordenamiento normativo vigente, que agrava la situación del autor a la luz de sus motivaciones reprochables? Como ya se ha adelantado, esta pregunta obtiene respuesta en la tesis de Müssig. Así como resultaba extraño separar los motivos de los hechos (cf. supra), "también es extraño -sostiene Peralta- decir que se castigan meros pensamientos o deseos cuando estos han constituido la razón que ha tenido el sujeto para actuar". Ahora, "¿cómo se reflejan los motivos en un hecho?", pregunta Peralta. He aquí su respuesta:

La expresión 'reflejo en el hecho' es demasiado difusa como para ayudar a resolver este problema con precisión. Más bien parece una confesión de que hay una intuición que no se logra articular. No obstante ello, esa afirmación indica algo. Esa

${ }^{14}$ Sobre lo mismo, véase Al-Hakim, M., "Making Room for Hate Crime Legislation in Liberal Societies", en Criminal Law and Philosophy 4 (3), 2010, págs. 341-358. 
Matías Parmigiani

expresión tiene algo de verdad. El contenido de verdad puede divisarse cuando se entiende que los motivos tienen la función heurística de señalar un hecho más grave debido a la ausencia de justificación. Los motivos, cuando han sido la razón del sujeto para cometer el ilícito, están indicando la falta total de justificación de la conducta. Por ello, efectivamente, sí se reflejan en el hecho y no se castigan de manera autónoma. Señalan que ante un hecho de gravedad ocho, indicado por el tipo, no se puede reducir la pena a raíz de alguna justificación, pues el hecho está completamente injustificado. Y, efectivamente, el motivo se encuentra 'reflejado' en el hecho, porque este ha sido la razón para cometerlo. Mientras justificaciones totales o parciales también se reflejan en el hecho, cuando el autor obra en virtud de ellas y no realiza así un ilícito o realiza uno menos grave ${ }^{15}$.

Y luego añade:

El motivo reprochable significa, así, haberse motivado por algo que no tiene ninguna relevancia eximente o atenuante del ilícito. El legislador, al tipificar los motivos reprochables, no está sancionando las motivaciones de manera independiente del hecho, así como tampoco lo hace cuando tipifica las causas de justificación. Está simplemente definiendo su gravedad según el nivel de (in)justificación (ibíd.).

\section{II.1. Los motivos: ¿metáforas o indicios?}

Que los motivos reprochables cumplan una función heurística en el planteo de Peralta resulta un dato más que relevante en todo esto. Existe una disputa sumamente extendida en la historiografía científica a propósito del papel que han de desempeñar las teorías en relación

${ }^{15}$ Peralta, J. M., Motivos reprochables. Una investigación acerca de la relevancia de las motivaciones individuales para el Derecho penal liberal, Madrid, Marcial Pons, 2012, pág. 208. 
a los hechos. Entre las cuestiones disputadas, destaca la del estatuto metafísico que detentarían los términos teoréticos. Dos bandos principales suelen enfrentarse entre sí: de un lado, las distintas variantes del realismo epistemológico y metafísico; del otro, las distintas variantes del instrumentalismo epistemológico (a veces también llamado 'idealismo' o 'anti-realismo'), las cuales sostienen que a los fines de ordenar la realidad y posibilitar un comportamiento predictivo de ciertos fenómenos -las funciones eminentes de la ciencia-, no es necesario postular que términos teoréticos tales como 'gen' o 'campo gravitacional' tengan un correlato metafísico convencional. Para el instrumentalista, mientras la ciencia logre ofrecer una descripción abreviada del comportamiento espacio-temporal de ciertos objetos, permitiendo salvar las apariencias, no habrá necesidad de efectuar saltos ontológicos adicionales ${ }^{16}$.

Las presentes disquisiciones vienen a cuento porque no resulta sencillo descifrar la postura que asume Peralta en relación con el modo en que la dogmática jurídica y la teoría general del delito deberían concebir las motivaciones reprochables. Si ellas han de cumplir el papel heurístico o instrumental de señalar aquellos hechos (delictivos) para los que no es posible hallar razones justificantes, ¿será porque estas motivaciones no hacen referencia a entidades realmente existentes?

Por lo visto, no exactamente. En realidad, lo que dice Peralta es que las motivaciones reprochables que figuran en las legislaciones positivas como elementos agravantes del ilícito, contrariamente a lo que podría imaginarse, no equivalen ni hacen referencia "a una cuestión subjetiva". Como él mismo aclara:

${ }^{16}$ Feyerabend, Paul, "Realism and Instrumentalism: Comments on the Logic of Factual Support", en Realism, Rationalism and Scientific Method. Philosophical Papers, Vol. 1. Cambridge University Press, Cambridge, 1981, págs. 176-202, pág. 176; Laudan, L., "Realism without the Real", en Philosophy of Science, 51, 1. (Mar.), 1984, págs. 156-162. 
Matías Parmigiani

Hasta aquí se ha hablado de motivos reprochables como algo subjetivo solo para tornar la discusión más comprensible, así como las causas de justificación son tematizadas normalmente también como casos que deben motivar al sujeto, aunque luego, al analizar los elementos subjetivos requeridos, se diga otra cosa. Los motivos siempre han sido entendidos como algo relativo a la mente del sujeto actuante y, por tanto, para dar cuenta de lo que ellos señalan resultó necesario mostrar que, en efecto, normalmente acompañan una situación de reducción del ilícito. Pero a partir de ahora dicha metodología debe ser abandonada, pues conduce a confusión. El obrar por motivos reprochables no es un caso de injusto máximo, de la misma manera que el obrar por motivos reprochables tampoco es un caso de injusto atenuado. Los motivos solo acompañan regularmente dichas variaciones, pues estas se encuentran justificadas de modo independiente ${ }^{17}$.

Al rechazar la manera de hablar que tilda a los motivos reprochables de algo subjetivo o "relativo a la mente del sujeto" y proponer en su reemplazo una nueva modalidad discursiva, Peralta no parece estar asumiendo un anti-realismo negatorio de la existencia de las motivaciones subjetivas. Por el contrario, es porque confía en su existencia y porque, siguiendo a Ferrajoli, les ha conferido un estatuto por demás prominente, que insiste en separar tajantemente las motivaciones subjetivas de aquellas motivaciones a las que se refiere nominalmente el Derecho penal. Más aún, tan poco anti-realista es la postura de Peralta, que en varios pasajes de su trabajo opta por emplear el término 'real'. Así, por ejemplo, podrá decir al inicio del capítulo IV de la 'Tercera Parte' que "los motivos reales del autor, en verdad, no son valorados en absoluto bajo esta defensa de su relevancia jurídico penal" y que hablar de motivos no debe constituir "más que una metáfora que describe un epifenómeno que acompaña a un injusto no reducido"18. Y así también

${ }^{17}$ Peralta, J. M., Motivos reprochables. Una investigación acerca de la relevancia de las motivaciones individuales para el Derecho penal liberal, Madrid, Marcial Pons, 2012, pág. 269.

${ }^{18}$ Ibídem, pág. 261. 
podrá afirmar en el último párrafo de su trabajo que "los motivos reales del autor no pueden ser objeto de valoración penal"19.

Ignoro si en verdad es posible postular una variante no necesariamente anti-realista del instrumentalismo, la cual bien podría atreverse a objetar que las entidades teoréticas postuladas por una teoría en efecto existan, sean cuales sean los criterios que elijamos para fijar su existencia (perceptibilidad pública, el ser mencionado en una ley generalmente aceptada, ser mencionado en una ley 'causal', etc. $)^{20}$. Mientras cierto tipo de entidades permitan salvar las apariencias, una teoría podría considerar su mención como una útil façon de parler, sin por eso negar que, llegado cierto momento, a estas entidades pudieran llegar a aplicársele los mismos criterios que determinan la existencia de otras entidades más universalmente reconocidas. Sin embargo, tampoco sería esto lo que propone Peralta cuando decide tratar las motivaciones reprochables como metáforas útiles, ya que su idea parece ser que las motivaciones reprochables que el Derecho penal toma como relevantes no tienen nada que ver con los estados subjetivos de conciencia o los motivos reales como la codicia o el odio racial y religioso. Pero entonces, ¿con qué tienen que ver las motivaciones reprochables?

En general, decimos que para comprender la acción de un agente (si este "estaba robando, jugando con un arma u ofreciéndola en venta") ${ }^{21}$, necesitamos averiguar qué quería hacer, i.e. comprender su intención. Pues bien, si los motivos forman parte de la intención y sucede que, a menos que conozcamos la intención de un agente, no lograremos dilucidar si una acción le era atribuible o imputable, cualquier esquema de atribución de acciones necesariamente se verá obligado a indagar en cuestiones internas como los motivos a fin de imputarle a un sujeto cierta situación objetiva, incluido el esquema empleado por el Derecho

${ }^{19}$ Ibídem, pág. 312.

${ }^{20}$ Maxwell, G., "El estatus ontológico de las entidades teóricas", en Olivé Morett, L. R. y Pérez Ransanz, A. R., Filosofia de la ciencia: teoría y observación. UNAM: Siglo XXI Editores, 1989, pág. 136.

${ }^{21}$ Peralta, J. M., Motivos reprochables. Una investigación acerca de la relevancia de las motivaciones individuales para el Derecho penal liberal, Madrid, Marcial Pons, 2012, pág. 166. 
Matías Parmigiani

penal $^{22}$. Esto no significa que los motivos o las intenciones deban dictaminar cómo medir una pena, ya que esto implicaría efectuar un injustificable salto lógico, como bien advierte Peralta ${ }^{23}$. Pero en cualquier caso, estos motivos o intenciones se comportarán a la manera de indicios o pruebas de la imputabilidad de una acción.

Como acaba de constatarse, una motivación posee carácter indiciario o probatorio cuando ella constituye un dato relevante para dirimir la imputabilidad de una acción a un agente. Ahora bien, ¿en qué sentido poseerán un carácter indiciario, no ya las motivaciones subjetivas, sino las motivaciones reprochables? ${ }^{24}$. En el único sentido en que las motivaciones reprochables podrían reunir cierto carácter indiciario, este ha de ser entendido en tanto prueba (parcial o total) de la imputabilidad de una situación objetiva que el Derecho penal quiere evitar (cf. ibíd.). Sin embargo, tan pronto como Peralta establece que las motivaciones reprochables nada tienen que ver con las motivaciones subjetivas o reales, puesto que aquellas constituyen una metáfora conveniente o un mero epifenómeno de casos de reducción del ilícito ${ }^{25}$, aquel presunto carácter indiciario parece perder su condición de tal. En consecuencia, dado que las motivaciones reprochables no guardan vínculo alguno con las motivaciones subjetivas o reales, aunque sí con la ausencia de causales o razones de justificación (ej. estado de necesidad, auto-puesta en peligro de la víctima, etc.), se abren dos posibilidades interpretativas: o bien aparece como un sinsentido hablar del carácter indiciario de las motivaciones reprochables, o bien este carácter ha de buscarse en otro sitio.

En cierta medida, Peralta parece haber encontrado este sitio cuando sostiene, según se viera, que "los motivos (reprochables) tienen la función heurística de señalar -o indicar, como lo dice más abajo- un hecho más grave debido a la ausencia de justificación"26, con lo que el carácter indiciario de una motivación parece entenderse

22 Ibidem, pág. 173.

${ }^{23}$ Ibídem, págs. 166-173.

${ }^{24}$ Ibídem, pág. 304.

${ }^{25}$ Ibídem, págs. 269-270.

${ }^{26}$ Ibidem, pág. 280. 
ahora como su potencialidad de señalar un hecho injustificable. No obstante, observado el mismo fenómeno bajo otro prisma, lo que en realidad se advierte es que en lugar de comportarse ofreciendo una señal de un hecho injustificable, lo único que ofrecen los motivos es una paráfrasis para decir exactamente lo mismo que podría decirse aludiendo a la ausencia de aquellas justificaciones que dotarían al hecho de mayor comprensibilidad. Lógicamente, que esto haya de ser así no es más que una consecuencia de lo que el mismo Peralta advierte: en su concepción, los motivos reprochables han de ser interpretados en tanto metáforas convenientes. Urge ahora preguntarse si esta interpretación no va reñida con la posibilidad de que los motivos reprochables actúen exhibiendo un carácter indiciario.

Ciertamente, no hace falta ser un avezado crítico literario para entender que lo que dota de carácter metafórico a una figura -a saber: la intencionalidad de quien la emplea- puede o no tener que ver con lo que le confiere un presunto carácter indiciario. De demostrarse, esta conexión será, en cualquier caso, un hecho contingente, siendo su verificabilidad deudora de otra clase de constataciones. Una huella en el camino, por ejemplo, puede ser indicio de la presencia de un caminante, aunque alguien pueda aludir a ella para referirse metafóricamente al conocido poema de Antonio Machado. Ahora bien, si las motivaciones reprochables constituyen tan solo una denominación para decir con ciertas palabras lo que podría decirse de otro modo, entonces lo único que cabe inferir es que ellas no se comportan de forma indiciaria con respecto a eso que, en efecto, puede decirse de otro modo, i.e. la ausencia de causales de justificación. Pero en realidad ni siquiera es tan solo esto lo que cabe desprender de aquí a modo de corolario provisional. Puestas las cosas en perspectiva, todo parecería funcionar más bien a la inversa del modo como lo concibe Peralta. Veamos por qué.

Dos hipótesis fácilmente contrastables se derivan de aceptar la vuelta de tuerca que propone Peralta. Según la primera de ellas, el nuevo concepto de motivaciones reprochables sería en principio compatible con el modo como han procedido históricamente los jueces penales, pues muchas veces sucedió que quien era sancionado 
Matías Parmigiani

con una pena agravada en virtud de sus motivaciones era sancionado tan solo ante la ausencia de razones justificantes, más allá de cuál fuere la comprensión que los jueces tuvieran de aquel concepto. De todos modos, como ello no siempre ha sido así y, además, como la aproximación subjetivista a las motivaciones ya no puede considerarse un enfoque aceptable, lo que plantea la segunda hipótesis es que ni los jueces ni la dogmática necesitan prescindir de las motivaciones en la determinación de las penas. Para ello, basta con que se aprecie el contenido metafórico que encierra este concepto. De acuerdo a esta segunda hipótesis, entonces, no sería necesario reescribir las leyes penales a los efectos de que se adecuen a un entendimiento cabalmente liberal del Derecho. Dado el caso de que se consagre el principio de legalidad (cf. supra), ellas estarán bien como están, con tal de que los dogmáticos y los jueces adviertan la terminología metafórica que emplean.

En resumidas cuentas, dado que ahora las motivaciones no existen excepto como una simple paráfrasis o metáfora de otra cosa -a saber: de la ausencia de causales de justificación-, será entonces esta ausencia la que señalará indiciariamente la presencia de cualesquiera motivaciones reprochables. Como podrá apreciarse, parecen ser las causales de justificación las que señalan o indican el menor o mayor grado de reprochabilidad motivacional y no a la inversa, como pretendía Peralta. Pero si estas motivaciones no son algo 'subjetivo' sino una conveniente 'herramienta heurística', surgen al menos dos preguntas importantes:

1) ¿En dónde reside la conveniencia del discurso sobre motivaciones reprochables? ¿Qué es lo que él dice que no pueda ser dicho por el discurso sobre causales de justificación sin resto o pérdida de contenido significativo?

2) ¿De qué tipos de motivaciones constituyen un indicio las causales de justificación? (cf. infra, sec. 7).

En la próxima sección se intentará mostrar que la condición fundamental para que el discurso sobre motivaciones reprochables siga cumpliendo una función indispensable en el Derecho penal es 
que ese discurso ya no sea interpretado como una simple metáfora para hablar de otra cosa (las causales de justificación), sino como la cara visible de un enfoque más comprensivo sobre las motivaciones que guarde un vínculo estrecho con el discurso sobre las causales de justificación, al cual deberá remitir -y esto es lo que Peralta habría alcanzado a intuir lúcidamente- de forma obligatoria. Una vez que se advierta esto, seguramente se comprenderá por qué son las causales de justificación las que siempre se comportarán como indicios de la presencia de motivaciones que merecen cierto reproche (jurídico), siendo estas motivaciones no menos reales que cualquiera de las motivaciones que suelen suscitar los tipos más comunes de reproche que se constatan, por ejemplo, en el ámbito moral.

\section{Hacia un enfoque objetivista de las motivaciones "reprochables" y "reales"}

De acuerdo con la postura de Peralta, no resulta legítimo que los motivos reales, entendidos como estados subjetivos de conciencia, sean objeto de valoración penal ${ }^{27}$. Ahora bien, ¿qué sucedería si las motivaciones reales no fueran equivalentes a estados subjetivos de conciencia? Los dos acápites que integran esta sección se proponen ofrecer un enfoque alternativo de las motivaciones reales que, al tiempo que dé cuenta de lo que Peralta entiende -algo inexactamente- como 'las motivaciones subjetivas' que pertenecen al área de la moral, también consiga dar cuenta de las motivaciones que serían de neta incumbencia jurídica.

\section{III.1. Dejando atrás el solipsismo metodológico}

Luego de haber manifestado su acuerdo parcial con la tesis de Müssig, este es el modo en que Peralta ilustra su postura: 
Matías Parmigiani

Ahora cabe preguntarse cuál es el caso en el que, por ejemplo, un hecho de robo se encuentra injustificado y así se debe negar cualquier situación de necesidad por mínima y remota que sea. El ejemplo de las razones para un robo es central, porque permite explicar uno de los motivos más extendidos sin tener que agregar argumentos extra: el de la codicia. Lo que por codicia se quiere dar a entender o, mejor dicho, lo que debe entenderse por codicia no es un 'deseo irrefrenable de obtener ventajas patrimoniales', sino la ausencia de necesidad de obtenerlas. La codicia implica que aquella ventaja que el autor obtiene con el hecho no es necesaria para satisfacer el 'sustento propio o el de los suyos', sino algo superfluo que de ningún modo puede justificar injerencias en derechos de terceros. En efecto, como afirma Streng, en la medición de la pena 'las circunstancias próximas al estado de necesidad deben atenuar y las cercanas a los motivos reprochables deben agravar', pero justamente porque estos últimos niegan toda posibilidad de las primeras ${ }^{28}$.

Al escribir "lo que debe entenderse por codicia no es un 'deseo irrefrenable de obtener ventajas patrimoniales', sino la ausencia de necesidad de obtenerlas", Peralta parece alzarse con la razón al menos en un sentido. Hoy, luego de que el solipsismo metodológico de procedencia cartesiana fuera definitivamente abandonado como un modo de aproximación a los estados mentales ${ }^{29}$, resultaría un tanto extraño pretender que la codicia - por no hablar de otras tantas motivaciones y/o creencias- no sea más que un 'episodio interno' identificable por introspección fenomenológica, algo que hace muchos años resultaba bastante más habitual afirmar" ${ }^{30}$. "Una de las ideas filosóficas más peligrosas -supo decir L. Wittgenstein con respecto a las creencias- es, curiosamente, la de que pensamos con la cabeza o en la cabeza" ${ }^{1}$.

${ }^{28}$ Ibídem, pág. 251.

${ }^{29}$ Putnam, H., "The Meaning of 'Meaning'", en Mind, Language and Reality. Philosophical Papers, Vol. 2, Cambridge University Press, Cambridge, 1975, pág. 220.

30 Sellars, W., Ciencia, percepción y realidad, traducción de V. Sánchez de Zavala. Tecnos, Madrid, 1971, cap. III y IV.

${ }^{31}$ Wittgenstein, L., Zettel, Basil Blackwell, Londres, 1967. 
¿Pero no transcurren nuestras motivaciones y creencias efectivamente en la cabeza y en nuestro interior? Aunque esto no podría negarse $a$ priori, hoy ya no parece sensato tomarlo como la última palabra. De manera que si este es el sentido que cabe detectar en la apreciación de Peralta (un sentido anti o post-cartesiano, según podríamos bautizar1o), es en este sentido que ella suena convincente.

Como sea, existe una gran diferencia entre sostener por vía negativa que los estados mentales no son identificables tan solo por introspección fenomenológica y decir afirmativamente cómo nos las ingeniamos para identificar un estado mental, más allá de cuál sea el lugar que le corresponde en el orden natural de las cosas (básicamente, si dentro o fuera de la cabeza). Es este paso adicional, entonces, el que uno debe atreverse a dar para completar todo el recorrido. Uno de los problemas centrales suscitados por la aproximación tradicional o clásica a los estados mentales, según denominación de Sellars ${ }^{32}$, fue el de cómo determinar el contenido de verdad de las afirmaciones que atribuyen ciertos predicados mentales a los agentes. En efecto, si el contenido de verdad de afirmaciones tales como ' $X$ cree que $p$ ' o ' $X$ desea q' dependiera solamente de lo que $\mathrm{X}$ dijera 'creer' o 'desear', caeríamos en el más absoluto solipsismo ${ }^{33}$.

Pero aún más importante que este, es el problema de la justificación para creer o desear ciertas cosas. Como sabemos, una cosa son los criterios para determinar si lo que $\mathrm{X}$ dice creer o desear es efectivamente lo que $\mathrm{X}$ cree o desea -problema que podríamos denominar 'fáctico' o ‘de atribución' 34 - y otra cosa son los criterios para determi-

32 Sellars, W., Ciencia, percepción y realidad, traducción de V. Sánchez de Zavala. Tecnos, Madrid, 1971, pág. 190.

${ }^{33} \mathrm{Al}$ respecto, véase Moran, R., Authority and Estrangement. An Essay on Self-Knowledge, Princeton University Press, Princeton, 2001; Lazos, E., "Autoconocimiento: una idea tensa", en Diánoia, vol. LIII, número 6, 2008, págs. 169-188.

${ }^{34}$ Aunque no estrictamente fáctico. Una razón para creer que lo que dice $\mathrm{X}$ es verdadero es que $\mathrm{X}$ sea sincero. ¿Pero cómo determinamos que $\mathrm{X}$ está siendo sincero? A veces, la única forma de hacerlo es evaluando las razones que $\mathrm{X}$ tendría para mentir en una situación concreta, aun si su tendencia a la sinceridad fuera una disposición de la que hubiera dado muestras sobradas 
Matías Parmigiani

nar si a X le asiste el derecho para creer o desear lo que cree o desea, más allá de qué sea esto. A diferencia del anterior, este problema de justificación, como se adivinará, concita un tratamiento auténticamente evaluativo.

Retomando ahora sí el caso de la codicia, resulta natural que concebida en tanto que 'episodio interno' o 'privado' de un agente, ella haya podido estar durante tanto tiempo asociada a un 'deseo irrefrenable de obtener ciertas ventajas patrimoniales'. Igualmente natural resulta que ella haya llegado a asumir al menos una doble faceta característica: fenomenológicamente, la de manifestarse como el correlato de un impulso psicológico muy vívido o algo semejante; y, materialmente, la de parecerse a una suerte de descarga eléctrica producida a nivel del córtex cerebral o algo semejante.

Sin embargo, así como solo muy injustamente alguien se arrogará el derecho de negar que esto es, efectivamente, lo que la codicia podría llegar a significar -estando uno facultado para descubrir lo que implica 'codiciar' a partir de tener ciertos impulsos o mediante la percepción de ciertas descargas eléctricas en una pantalla de laboratorio conectada a nuestro cerebro por medio de electrodos (pongamos por caso)-, también es cierto que la codicia encierra un contenido proposicional que dista de ser evaluativamente neutro. En esencia, porque al llamar a alguien 'codicioso' casi nunca estamos asumiendo una descripción sobre su persona que de una $u$ otra manera no involucre un elemento de desaprobación. Y si lo que está en cuestión es cómo podemos convencer a un observador externo de que cierto episodio interno o privado de nuestra consciencia se trataría de un auténtico ejemplar de codicia, difícilmente bastará con ofrecer una descripción empírica de él; en su lugar, lo que necesitaremos hacer es, como diría Sellars, colocarlo "en el espacio lógico de las razones, de justificar lo que uno diga y ser capaces de justificarlo" 35 .

a lo largo de su vida (véase Williams, B., Verdad y veracidad, trad. Alberto Enrique Álvarez y Rocío Orsi. Tusquets Editores, Barcelona, 2006.).

${ }^{35}$ Sellars, W., Ciencia, percepción y realidad, traducción de V. Sánchez de Zavala. Tecnos, Madrid, 1971, pág. 182. 
Hasta aquí, simplemente parece no haber nada en esta aproximación a la codicia que contradiga la postura de Peralta. Más aún, de darse un paso adicional, se comprobaría que no hay forma de identificar un estado mental como un caso de codicia a menos que verifiquemos que no están dadas las razones justificantes que obligarían a transformar ese caso en otra cosa. Consecuentemente, ¿en qué otra cosa se transformaría ese supuesto estado mental de llegar a concurrir condiciones tales como la imposibilidad de obtener el sustento propio y el de los suyos mediante el cual el Código Penal argentino, por ejemplo, caracteriza la situación de quien, de otra manera, delinquiría injustificadamente?

Uno dirá, naturalmente, que se transformaría en un deseo parcialmente justificado o comprensible de obtener ventajas patrimoniales, sin importar cuán intrínsecamente irrefrenable sea el mismo o cuán poderoso se le aparezca a fuero interno al sujeto que lo detenta. De todos modos, al objeto de demostrar que los motivos, en el sentido jurídico-penalmente relevante, de ninguna manera hacen referencia a una cuestión subjetiva -que es lo que parece querer demostrar Peralta cuando sugiere abandonar la metodología que refiere a los motivos "como algo relativo a la mente del sujeto actuante"36-, las pruebas que hasta ahora hemos cosechado distan de ser suficientes. Y, en cualquier caso, hablar acerca de deseos reales (justificados o no, comprensibles o no, etc.) parece ser todavía una cuestión inevitable.

\section{2. En busca de una alternativa metodológica}

Según podría resumirse en breves líneas la postura de Peralta, cuando ante un hecho delictivo puntual corresponde una agravante por motivos reprochables, ello se debe a que no se constata la presencia de ninguna de las razones justificantes que permitirían disminuir la ilicitud del hecho y, con esto, el grado de reproche penal. Sin embargo, ¿qué diferencia existe entre afirmar esto y afirmar, por otro lado, que la ausencia de razones justificantes torna más reprochable un hecho,

${ }^{36}$ Peralta, J. M., Motivos reprochables. Una investigación acerca de la relevancia de las motivaciones individuales para el Derecho penal liberal, Madrid, Marcial Pons, 2012, pág. 269. 
Matías Parmigiani

debido a que son esas razones las que tornan impermisible (o injustificable) la posesión de ciertos motivos o deseos, así como la decisión de actuar sobre la base de los mismos? Al parecer, ninguna en absoluto.

De manera análoga, cuando aquella agravante no corresponde, ello se debe a que ciertas situaciones (estado de necesidad, auto-puesta en peligro de la víctima, dificultad para ganarse el sustento, etc.) tornan comprensible la realización de ciertas acciones, restándole un grado de ilicitud. Sin embargo, ¿qué diferencia existe entre afirmar esto y afirmar, por otro lado, que son estas situaciones las que tornan más permisible la realización de ciertas acciones precisamente porque son estas situaciones las que permiten comprender que se tengan determinados deseos (y/o creencias) y se los utilice como base de ciertas acciones? Al parecer, entre una y otra afirmación tampoco parece haber ninguna diferencia significativa ${ }^{37}$.

Un razonamiento sencillo será de ayuda para arrojar luz sobre este punto. En los casos de robos movidos por la codicia, ¿qué significa la ausencia de necesidad de obtener ventajas patrimoniales referida por Peralta? ¿Acaso significa que un agente carecerá absolutamente de la necesidad de obtener o seguir obteniendo ventajas patrimoniales? Que este no parece ser el caso lo sabemos de constatar cuán contadas son las personas de quienes podría afirmarse algo así. Por ejemplo, ¿qué diríamos de los agentes que a pesar de poseer trabajos bien remunerados y vivir una vida sin grandes privaciones ni percances, aún no han logrado asegurarse el colchón de ahorros que los desvincularía de sus obligaciones laborales? ¿Afirmaríamos que no se hallan bajo la necesidad de obtener (o seguir obteniendo) ventajas patrimoniales? Muy difícilmente. Ergo, todo indicaría que no es en la ausencia de necesidad de obtener ventajas patrimoniales donde habría de buscarse la clave que defina la codicia. En su lugar, ella parece residir en la ausencia de necesidad de obtener ventajas patrimoniales por medios no permitidos, ya sea desde el punto de vista moral (medios como el

${ }^{37} \mathrm{Al}$ respecto, véase Al-Hakim, M., "Making Room for Hate Crime Legislation in Liberal Societies", en Criminal Law and Philosophy 4 (3), 2010, págs. 341-358. 
engaño, la mentira, la adulación o -en una ética marxista, pongamos por caso- la plusvalía), ya sea desde un punto de vista estrictamente jurídico (medios como el robo o la estafa).

Por supuesto, semejante comprensión instrumental de la acción no es lo único novedoso que se añade a este esquema explicativo general. Así, una vez que el medio empleado adquiere un papel indiciario en la detección de la motivación, también adquirirá un papel revelador el objetivo de máxima por el que dicho medio se emplee, por lo mismo por lo que habría advertido Aristóteles: bien puede que los medios sean constitutivos de los fines ${ }^{38}$. Esto se pone de manifiesto tanto en la actitud de quien roba para salir de una situación de apremio económico como en la actitud de quien hace lo propio pero para seguir aumentando su patrimonio, dos objetivos de máxima bastante disímiles que arrojan explicaciones de la acción igualmente discordantes. Medios y fines (u objetivos) son, por ende, estrictamente necesarios para determinar el carácter de una motivación, con lo que muy improbablemente llegaremos a realizar una atribución de 'codicia' que resulte creíble a menos que apelemos conjuntamente a estos dos elementos $^{39}$. Piénsese si no en la siguiente contraposición de deseos, deliberadamente descriptos de forma discreta:

${ }^{38}$ Wiggins, D., "Deliberation and Practical Reason", en Needs, Values, Truth, Oxford University Press, Oxford, 1998, págs. 215-238.

${ }^{39}$ En consonancia con este planteo, afirma G. H. von Wright en Sobre la libertad humana: "Una clase importante de motivos está constituida por las 'pasiones' tales como celos, odio, avaricia. Tienden a 'mover' a la gente a la acción; bajo su influencia las personas hacen diversas cosas. Que una persona, por ejemplo, odie a otra se plasmará normalmente en varios 'fines' de acción que luego esta persona sigue. Puede querer infligir daño al objeto de su odio. Tener tales objetivos no es tanto una 'consecuencia' de su pasión como algo 'constitutivo' de ella; sus objetivos son los 'criterios' de acuerdo con los cuales le atribuimos la pasión en cuestión" (Von Wright, G. H., Sobre la libertad humana, traducción de Amparo Gómez. Paidós, Barcelona, 2002, pág. 79). A diferencia de von Wright, quien vincula objetivos y motivos de un modo constitutivo, Peralta cree necesario trazar una distinción un tanto más tajante entre ellos. Escribe al respecto: "Los motivos harían referencia a por qué obró el agente, mirando hacia el pasado, y los objetivos a para 
Matías Parmigiani

(1) Deseo de obtener ventajas patrimoniales por medio de un trabajo legal.

(2) Deseo de obtener ventajas patrimoniales por medio de un trabajo ilegal.

Así como están referidos, resulta casi imposible determinar cuál de ellos representa un caso de codicia sin traer a colación una cantidad nada despreciable de información adicional relativa a las características personales del portador del deseo, a las circunstancias que lo rodean y tantas otras que podrían mencionarse.

Desde luego, en lo que atañe al terreno estrictamente penal en el que se mueven las reflexiones de Peralta, lo único que parece importar para detectar el tipo de motivación implicada es la determinación de las posibles causales de justificación. Pero ¿cómo hacer para determinar que en un caso concreto de robo, por ejemplo, se verifique la ausencia de necesidad de obtener ventajas patrimoniales $y$, con esto, una motivación como la codicia, que es la que debe fundar el máximo de pena?

Parece en principio sensato descartar una salida que pretenda versar tan solo sobre el posible valor de los objetivos que perseguiría el agente. En este sentido, la advertencia que formula Peralta es de un valor inconmensurable: por más loables que sean los objetivos que persigue un ladrón de bancos (como donar el dinero robado a los pobres, por ejemplo, a la manera de Robin Hood), si no concurre una causal de justificación jurídicamente prevista en la legislación,

qué realizó su conducta, mirando más bien hacia el futuro. Así, se puede distinguir entre quien obra para ganar dinero, porque quiere salir de su situación de pobreza, de quien delinque para ganar dinero, pero debido a que es codicioso. Ambos tienen el mismo objetivo, pero diferentes motivos. De esta manera, motivos y objetivos de la acción parecen dos cosas diferentes, por lo que, por ejemplo, el 'fin de lucro' (art. 176.7 CP ar.; art. $234 \mathrm{CP}$ es.; $\S 203.5 \mathrm{StGB}$ ) no responde exactamente al mismo esquema de explicación y justificación al obrar por codicia" (Peralta, J. M., Motivos reprochables. Una investigación acerca de la relevancia de las motivaciones individuales para el Derecho penal liberal, Madrid, Marcial Pons, 2012, págs. 32-33). En lo que sigue, qué pienso exactamente de la relación entre motivos y objetivos espero que se ponga de manifiesto mediante un ejemplo. 
la motivación para cometer el robo bancario deberá considerarse por igual como un caso de codicia. De cualquier modo, incluso formulada esta advertencia, ¿quién podría negar que lo que sea que en un agente se encuentre operando no vaya a ser efectivamente un estado subjetivo o real, tan subjetivo o real como la motivación que desde el sentido común se nos suele atribuir? ${ }^{40}$

En este acápite ha intentado formularse una caracterización alternativa de las motivaciones subjetivas o reales capaz de explicar por qué, a los fines de proceder a su identificación en el amplio universo de la moralidad, las denominadas causales o razones justificatorias desempeñarían el mismo papel que desempeñarían para Peralta en el ámbito jurídico.

Ahora bien, si este tipo de caracterización es válido para uno y otro ámbito, ¿por qué no admitir abiertamente que el discurso del sentido común sobre las pasiones y motivaciones humanas no sea más que una metáfora para referirnos a lo que podría decirse de otro modo? Después de todo, tal vez ese discurso no sea sino el olvidable resabio de una aproximación solipsista y cartesiana a la psicología. ¿Pero por qué entonces no atrevernos a ir incluso más allá y reconocer también que este mismo discurso que reprocha o desaprueba la codicia desmedida del avaro, por ejemplo, no sea más que una concatenación de palabras con perfecto sentido aunque sin ningún tipo de referente real?

La principal razón para rechazar esta sugerencia remite a la diferencia que existe entre el objeto al que puede estar dirigido un juicio de reproche y los criterios indiciarios que empleamos a los efectos de identificar este objeto. Por cierto, bien puede ser verdad que las causales de justificación constituyan los criterios de identificación eminentes que deberíamos emplear tanto en el ámbito jurídico como en el ámbito moral. Asimismo, igualmente valedero puede ser que sin una manera clara y transparente de concebir estos criterios, la práctica de agravar las penas a tenor de la gravedad de los ilícitos nunca consiga

${ }^{40}$ Jackson, F. y Pettit, P., "Functionalism and Broad Content", en Jackson, F., Pettit, P. y Smith, M. (autores), Mind, Morality and Explanation (Selected Collaborations). Oxford University Press, Oxford, 2004, págs. 108-114. 
ofrecer un resguardo sólido para el principio de legalidad. Ahora bien, por más claros y cristalinos que resulten estos criterios, ellos nunca nos darán lo que necesitamos a los efectos de fundar un juicio de reproche. $\mathrm{Y}$ es que, sin nada que reprochar, sin un objeto a la vista, difícilmente pueda haber un juicio de reproche posible.

Por otro lado, si se opta por un camino alternativo tendiente a admitir sin más que el habla de las motivaciones reprochables relativa a la dogmática pudiera versar sobre el mismo objeto que el de las motivaciones subjetivas o reales, muchos temerán por la probabilidad de que se genere una consecuencia ciertamente peligrosa, cual sería la de que empiecen a levantarse las barreras que de momento impiden que el Derecho -y, con él, el Estado- se inmiscuya en cualquiera de las motivaciones humanas. Es cierto que tal implicancia extrema, según se imaginará, parece francamente irrisoria desde un punto de vista estrictamente burocrático del rol del Estado. Pero suponiendo que algo así se generara y un mundo como el de 1984 se instaurara entre nosotros (por citar un caso realmente extremo), sería evidente que las consecuencias normativas que se seguirían resultarían bastante difíciles de asimilar desde una concepción liberal del Estado, comoquiera se nos ocurra definirla.

No obstante, mientras todavía exista una alternativa viable para diferenciar, dentro del vasto universo de los motivos reales (o morales), aquellos que puedan ser de neta incumbencia jurídica, ninguna implicancia semejante cabría inferir de mi planteo. Resta explicar, entonces, de qué manera podría ser esto posible.

\section{Una nota general sobre los conceptos de pena y reproche}

Al inicio de esta recensión se dijo que más allá de cuál sea el liberalismo por el que aboga Peralta, a los fines de abrazar una concepción liberal del sistema jurídico y del poder punitivo en un Estado de derecho, no habría necesidad de buscar apoyo en un dogma como el que capturan las palabras de Ferrajoli. Es verdad que luego de cierto escrutinio filosófico, la tentación parece difícil de resistir. Los defensores del dogma 
son poderosos y constituye una tendencia ampliamente difundida entre los filósofos del derecho de tradición liberal la de diferenciar tajantemente entre la supuesta "interioridad de la moral" y la típica "exterioridad del derecho" 41.

Sin embargo, por gravoso que sea el peso de la tradición, hay una razón para repudiar esta diferenciación que ya no puede permanecer oculta durante más tiempo. Sucintamente, lo que ella viene a expresar es que así como la moral y, de modo singular, el reproche moral pueden versar sobre los estados mentales o anímicos de las personas (como asimismo podrían versar sobre sus disposiciones, rasgos del carácter y concepciones del mundo) ${ }^{42}$, también el derecho y el reproche jurídico podrán hacerlo, por lo menos una vez que estos estados pasan a interpretarse en virtud de una aproximación post-cartesiana a la psicología $^{43}$ ligada a una formulación alternativa de la doctrina liberal.

Dos acotaciones generales son necesarias a propósito del concepto de reproche. La primera de ellas está relacionada con una reflexión que el propio Peralta ensaya en una sección de su libro. "No es curioso ni contradictorio afirmar que se prohíbe algo porque está mal -escribesin que ese mensaje deba llegar en tono de reproche a alguien"44. A lo que agrega: "Por el contrario, el contenido desde el punto de vista del Estado no tiene por qué ser compartido por el destinatario de la pena" 45 . Concedido: no es curioso ni contradictorio afirmar que se prohíba algo porque esté mal sin que ese mensaje deba llegar en tono de reproche a alguien. En efecto, el momento de prohibición

${ }^{41}$ Kant, I., Metafisica de las costumbres, traducción de Adela Cortina y Jesús Conill Sancho, Altaya-Tecno, Madrid, 1997, pág. 29.

${ }^{42}$ Asimismo, véase Sher, G., "Blame for Traits", en Noûs 35:1, 2011, págs. 146161; Al-Hakim, M., "Making Room for Hate Crime Legislation in Liberal Societies", en Criminal Law and Philosophy 4 (3), 2010, págs. 341-358.

${ }^{43}$ Jackson, F. y Pettit, P., "Functionalism and Broad Content", en Jackson, F., Pettit, P. y Smith, M. (autores), Mind, Morality and Explanation (Selected Collaborations). Oxford University Press, Oxford, 2004, págs. 95-118.

${ }^{44}$ Peralta, J. M., Motivos reprochables. Una investigación acerca de la relevancia de las motivaciones individuales para el Derecho penal liberal, Madrid, Marcial Pons, pág. 111, 2012. 
Matías Parmigiani

es distinto del momento de reproche y no todo aquel que transgrede una prohibición merece un reproche por eso. ¿Quién merece un reproche? Básicamente, quien contravino una prohibición en ausencia de razones justificantes o excusas ${ }^{46}$. Pero incluso si no hubiera razones justificantes o excusas, alguien podría transgredir una prohibición amparado en una razón que podría estar en franca contradicción con la razón que esgrime el Estado para sostener la vigencia de la norma. Esto se torna manifiesto, por ejemplo, en los actos de desobediencia civil o también en algunos actos delictivos por medio de los cuales sus autores pretenden expresar su disconformidad con ciertos valores imperantes. Por eso, bien hace Peralta en remarcar a renglón seguido que el contenido correcto desde el punto de vista del Estado no tiene por qué ser compartido por el destinatario de la pena.

Siguiendo esta misma línea de razonamiento, la segunda acotación podría ensayarse en forma de pregunta: ¿sería curioso o contradictorio afirmar que se sanciona algo porque está mal aunque esta sanción no conllevara un auténtico juicio de reproche? Puesta a la inversa, la misma pregunta dirá: ¿sería curioso o contradictorio afirmar que el reproche que le dirigimos a alguien podría no estar acompañado, después de todo, por una especie de pena o sanción que pretendiera implementarse de modo más o menos formal? Aunque todo dependerá, en última instancia, de cómo entendamos los conceptos de pena y reproche, no parece haber mayores dificultades en contestar ambas preguntas por la negativa. Al menos desde un punto estrictamente lógico, los conceptos parecen ser independientes, más allá de que en la práctica terminen trabajando juntos ${ }^{47}$. Por idéntica razón, en principio no hay nada que impida formularle a alguien un juicio de reproche por sostener ciertas motivaciones sin pretender que eso mismo vaya acompañado de una pena o sanción que implique la inflicción de cierto tipo de sufrimiento, tal como la privación de la libertad.

${ }^{46}$ Scanlon, T., Moral Dimensions: Permissibility, Meaning, Blame, Cambridge, Harvard University Press, 2008, pág. 124.

${ }^{4}$ Íbídem pág. 122-123. 
Desde luego, para que el reproche tenga sentido, trátese de una reacción que tenemos frente a alguien, trátese de un juicio que le dirigimos, el mismo deberá partir del reconocimiento de que el agente reprochado comparte (o debería compartir) con el agente que efectúa el reproche un núcleo de relaciones y expectativas comunes más o menos estrecho ${ }^{48}$. Paralelamente, si el reproche expresa una defraudación de expectativas, lo lógico es que la estructura motivacional de los agentes reprochados vaya acompañada de una dosis de sufrimiento, la cual, por lo general, tenderá a reflejarse bajo la forma del remordimiento y otras sensaciones análogas ${ }^{49}$. Ergo, no sería del todo cierto, como antes se dijo, que el reproche no comporte alguna idea de sufrimiento. Lo que sí parece más sensato afirmar es que no necesariamente comportará esa dosis de sufrimiento que suelen infligir las modalidades más conocidas de la sanción penal comúnmente entendida.

A priori, estas acotaciones calzarían a la perfección con algo que desliza Peralta inmediatamente a continuación del pasaje anterior: "La idea de que la pena deba expresar censura a modos de ver el mundo - escribe- no se sigue de la definición de pena, sino que es un postulado valorativo que se agrega al de la definición de pena como un fin que esta debe cumplir" ${ }^{50}$. En esta cita, según se advertirá, el concepto de reproche pareciera hallar su equivalente en la expresión 'censura a modos de ver el mundo', que no pasa de ser ni más ni menos que una de las tantas caracterizaciones que podríamos ofrecer del concepto de reproche a tenor de los objetivos que este persigue ${ }^{51}$.

${ }^{48}$ Ibídem, pág. 128 y ss. Fricker, Miranda, "What's the Point of Blame?" (Draft), en http://www.ucl.ac.uk/laws/jurisprudence/docs/2013/fricker_2013.pdf, pág. 17, 2013.

${ }^{49}$ Williams, B., "Internal Reasons and the Obscurity of Blame", en Making Sense of Humanity and Other Philosophical Papers, Cambridge University Press, Cambridge, 1995, pág. 41.

${ }^{50}$ Peralta, J. M., Motivos reprochables. Una investigación acerca de la relevancia de las motivaciones individuales para el Derecho penal liberal, Madrid, Marcial Pons, 2012, pág. 111.

${ }^{51}$ Nino, C. S., Introducción a la filosofia de la acción humana, Buenos Aires, EUDEBA, 1987; Williams, B., "Internal Reasons and the Obscurity of Blame", en Making Sense of Humanity and Other Philosophical Papers, 
Matías Parmigiani

A los efectos de reprocharle algo a una persona, esta persona debe encontrarse en falta. Ahora, así como "esta falta puede estar vinculada a una acción u omisión" de alguien,

... también puede relacionarse con los motivos, actitudes, disposiciones, o incluso con las creencias del agente reprochado (reprochamos en la gente los aspectos doxásticos de su racismo casi tanto como reprochamos en ella cualquier motivación que lo sostenga), y ciertamente reprochamos a la gente más allá de si los aspectos interiores de su vida se trasladan o no a su conducta ${ }^{52}$.

De cualquier modo, lo importante es que, exprese o no una censura a modos de ver el mundo, Peralta tiene razón en cuanto a que el concepto de reproche es absolutamente independiente del concepto de pena. Si no lo fuera, la consecuencia sería desastrosa, ya que todos podríamos ser penados incluso si los aspectos interiores de nuestra vida no se manifestaran externamente en nuestras conductas.

\section{Los conceptos de pena y reproche desde una formulación alternativa a la doctrina liberal}

¿Qué se requiere entonces para que este concepto amplio de reproche, lógicamente independiente de la idea de pena aunque compatible por lo demás con la posibilidad de censurar modos de ver el mundo o actitudes internas como los pensamientos y las motivaciones, pueda

Cambridge University Press, Cambridge, 1995, págs. 35-45; Sher, G., "Blame for Traits", en Noûs 35:1, 2001, págs. 146-161; Scanlon, T., Moral Dimensions: Permissibility, Meaning, Blame, Cambridge, Harvard University Press, 2008; Fricker, Miranda, "What's the Point of Blame?" (Draft), en http://www.ucl. ac.uk/laws/jurisprudence/docs/2013/fricker_2013.pdf, 2013.

${ }^{52}$ Fricker, Miranda, "What's the Point of Blame?" (Draft), en http://www. ucl.ac.uk/laws/jurisprudence/docs/2013/fricker_2013.pdf, pág. 12, 2013; sobre lo mismo, véase Sher, G., "Blame for Traits", en Noûs 35:1, 2001, págs. 156-157. 
fundar una aproximación liberal al poder punitivo de un Estado de derecho? Lo que se requiere, en primer lugar, es que nadie sea penado solo por el hecho de tener ciertas motivaciones, pensamientos, predisposiciones o rasgos del carácter. Sin embargo, de esto no se infiere que algunas motivaciones, pensamientos, predisposiciones o rasgos del carácter no puedan ser criticados, censurados o directamente reprochados desde el Estado, que es aparentemente la conclusión que muchos liberales, incluido Peralta, pretenden inferir.

Peralta sostiene que la teoría según la cual sería aceptable permitir que un Estado reproche a sus ciudadanos la infracción de las normas penales en virtud de razones que ese mismo Estado estime como válidas -teoría que él llama 'de la prevención general positiva'- no es criticable porque pretenda educar a través de la fuerza; es criticable porque pretende inculcar valores más allá del Derecho, se lo haga o no por la fuerza ${ }^{53}$. Sin embargo, ¿qué sentido tendría amenazar con pena ciertas acciones si lo que estuviera en cuestión no fuera precisamente la vigencia de cierta escala valorativa que debiera ser respetada aun si no fuera más que en virtud de que es lo que ha elegido una ciudadanía mayoritaria expresándose democráticamente en las urnas? ${ }^{54}$ En una economía capitalista, por ejemplo, a menudo no bastará con que el Estado dé por descontado o asuma sin más un valor como el de la propiedad privada. Dado el caso de que un marxista extremo transgrediera este valor y recibiera por ello una pena a cambio, ¿no sonaría ciertamente arbitrario que él no fuera expuesto a las razones que al menos desde el Estado se esgrimen para apoyar esta institución?

Pero más allá de esto, hay una cuestión importante que todavía resta considerar: ¿qué se infiere exactamente del hecho de que de la definición de pena no se siga el que esta deba expresar censura a modos de ver el mundo, sino que esta censura sea, como constata Peralta, "un postulado valorativo que se agrega al de la definición de

${ }^{53}$ Peralta, J. M., Motivos reprochables. Una investigación acerca de la relevancia de las motivaciones individuales para el Derecho penal liberal, Madrid, Marcial Pons, 2012, pág. 112, nota 97.

${ }^{54}$ Sobre el mismo argumento, véase ibídem, pág. 113 y ss. 
pena como un fin -extrínseco, según podríamos agregar- que esta debe cumplir"? Por lo pronto, y con independencia de cualquier otra inferencia, nada, absolutamente nada parece inferirse acerca de qué puede tener permitido el Estado hacer o no hacer, no ya en materia de penas, sino en materia de reproches. Peralta dice que "un Derecho penal que se dedique a tratar de modificar modos de pensar respecto de ciertos valores sociales no es un Derecho penal liberal". Si esto significa que un Estado no puede estar legitimado desde la doctrina liberal para modificar modos de pensar respecto de ciertos valores por vía del sistema penal y haciendo uso del aparato represivo de que dispone, la afirmación de Peralta es un justo llamado de precaución. Ahora, ¿ha de significar esto que un Derecho que se dedica a tratar de modificar modos de pensar respecto de ciertos valores sociales no puede reclamar para sí las cartas de un Derecho auténticamente liberal?

Esta segunda pregunta es importante porque nos invita a desviar la atención, aunque sea por un momento, del área estrictamente penal que integra el Derecho. Luego, entendiendo el Derecho liberal de modo amplio o liberal (valga la redundancia), ¿será cierto que no puede constituir una misión legítima por parte del Estado la de modificar ciertos modos de pensar? En principio, existen al menos dos maneras claramente diferenciables de respaldar esta pretensión.

Según la primera de ellas, que esto no pueda ser así no ha de significar sino, una vez más, que el Estado tiene vedada la posibilidad de inculcar modos de pensar apelando a herramientas que generen la impresión de que lo que se está haciendo pueda parecerse más a una forma de imposición que a una suerte de práctica persuasiva tendiente a lograr -por ponerlo a la manera de Habermas- el triunfo del mejor argumento. Para que ello suceda y la temida imposición aparezca como una amenaza en ciernes, no es necesario que el Estado pretenda modificar ciertos modos de pensar valiéndose del aparato represivo (esto, como acaba de corroborarse, no es lo que está aquí bajo discusión); la temida imposición también se manifestará cuando el Estado pretenda transformar las creencias de los ciudadanos, por ejemplo, fijando gravámenes o cargas impositivas diferenciales a ciertos medios o canales de difusión de creencias (como programas de radio 
o televisión, periódicos, conferencias, congresos, etc.) que sean de una orientación contraria a la instituida oficialmente, o también, por qué no, negándole la personería jurídica a ciertas asociaciones cuyos fines estatutarios resulten tan reprensibles moralmente (por ejemplo, promover el racismo y la xenofobia) que se torne necesario pronunciarse desaprobatoriamente sobre ellos. Aunque mucho podría discutirse en torno a este tópico, baste por el momento con asumir como válida esta primera explicación liberal de lo que no puede suceder cuando el Estado pretende transformar ciertos modos de pensar ${ }^{55}$.

Pasando entonces a la segunda explicación, lo que un liberal hará a fin de respaldar la pretensión de que 'no puede constituir una misión legítima por parte de un Estado modificar los modos de pensar de una ciudadanía' es definir estos modos de pensar de la forma más restrictiva posible. ¿Cómo podría hacerse esto? Según se ha sugerido en otro sitio $^{56}$, la distinción que aquí resulta crucial tomar en cuenta no es la que se deriva del par 'interioridad-exterioridad' -tal la distinción de Ferrajoli- sino la que cabe trazar entre aquellas acciones individuales que generan repercusiones intersubjetivas en las vidas de otros seres humanos y aquellas acciones que forman parte de lo que se considera la moral personal, privada o autorreferente, es decir, aquellas acciones vinculadas, ya sea con la auto-degradación de quien la ejecuta o con la posibilidad de satisfacer un ideal sumamente personalísimo de excelencia humana, como una vida dedicada a las letras o al deporte ${ }^{57}$. Sobre la base de esta distinción, lo que los liberales habrán de argüir no es que no pueda constituir una misión legítima por parte del Estado modificar los modos de pensar, de sentir o de ser de la ciudadanía. En tanto estas actitudes internas y disposiciones estén vinculadas con las

${ }^{55}$ Para una posición contraria, véase Wall, S., Liberalism, Perfectionism and Restraint, Cambridge University Press, Cambridge, 1998, págs. 27-123.

56 cf. supra, sec. 2; Parmigiani, M., "Liberalismo, sanción y reproche: Una revisión crítica del concepto de reproche en la teoría jurídico-penal de C. S. Nino" [de próxima aparición en Isonomía. Revista de Teoría y Filosofia del Derecho (N. $\left.{ }^{\circ} 39\right)$ ], 2013.

${ }^{57} \mathrm{Al}$ respecto, véase Nino, C. S., Introducción a la filosofia de la acción humana, Buenos Aires, EUDEBA, 1987, págs. 111-112. 
Matías Parmigiani

denominadas pautas de la moral intersubjetiva en las que se apoya el Derecho, al Estado le sería perfectamente lícito pronunciarse sobre ellas, ya sea formulando advertencias tendientes a evitar que estas pautas se infrinjan o, cuando eso no sucede, asumiendo una actitud directamente reprochadora ${ }^{58}$. Lo que más bien habrán de argüir es que no puede constituir una misión legítima por parte del Estado modificar aquellos modos de pensar, sentir o ser de la ciudadanía que guarden cualquier tipo de vínculo con lo que atañe a la moral personal o autorreferente de cada uno, e incluso quizá tampoco con aquellas pautas de la moral intersubjetiva que no hayan decantado en principios, normas y disposiciones debidamente codificadas en el Derecho positivo. Este es el coto que el Estado tendrá vedado transgredir bajo cualquier condición ${ }^{59}$.

En cuanto a lo segundo que ha de requerirse a fin de asegurar que este concepto amplio de reproche termine de propiciar una aproximación auténticamente liberal al poder punitivo de un Estado de derecho, una aproximación que no transgreda el coto recién citado, es que la práctica de agravar las penas en virtud de las motivaciones que puedan haber acompañado las conductas delictivas sea una práctica transparente y debidamente reglamentada. De otra forma, el principio

${ }^{58}$ Sobre el paralelismo lógico existente entre las prácticas de la advertencia y el reproche, véase Williams, B., "Internal Reasons and the Obscurity of Blame", en Making Sense of Humanity and Other Philosophical Papers, Cambridge University Press, Cambridge, 1995, págs. 35-45, pág. 40 y ss. "Si la expresión 'debió haber' [ought to have] resulta adecuada bajo la modalidad del reproche [blame] luego de pasada la ocasión -escribe Williams-, la expresión 'debe' [ought to] resultaba adecuada durante la ocasión bajo la modalidad de la advertencia [advice]" (pág. 40).

${ }^{59} \mathrm{En}$ su interpretación de Mill, quien fuera el primer autor en separar tajantemente estos dos ámbitos de la moral, M. Farrell se muestra incluso menos estricto que yo al definir el coto vedado. Él le atribuye a Mill la visión según la cual tanto el gobierno como la sociedad están autorizados a pronunciarse sobre todo lo relativo a la moral autorreferente de los individuos, siempre y cuando no recurran para ello a la utilización de coacciones legales o amenazas coactivas (Farrell, M. D., El derecho liberal, Abeledo Perrot, Buenos Aires, 1998, págs. 153-154). 
de legalidad definitorio del Estado de Derecho se vería vulnerado, tal como la primera estrategia argumentativa de Peralta se encargó fehacientemente de demostrar ${ }^{60}$.

\section{Comentarios finales}

A mi juicio, precisamente la gran virtud del trabajo de Peralta consiste en haber señalado el camino para que este segundo requisito pueda verse plasmado. Aquí, el faro que oficia de guía está representado por la dogmática penal, que es la que finalmente consigue ofrendar la tan ansiada reglamentación. De hecho, la mentada serie de justificaciones que vienen a reducir la gravedad del ilícito, disminuyendo con esto el grado de reproche penal, constituyen para Peralta, al menos bajo la interpretación sui generis que hace de las mismas (aunque no necesariamente), ni más ni menos que la salida que estaba aguardando para evitar correr el riesgo de que cualquier motivación humana pueda capturar la atención de los funcionarios estatales y/o pueda transformarse en presa fácil de su posible discrecionalidad.

A estas alturas, estamos obligados a notar que semejante formalismo no es baladí. Comparemos si no lo que sucede en los ámbitos más vastos e imprecisos de una moralidad ampliamente entendida ${ }^{61}$. Al no existir en estos ámbitos ni una reglamentación formal, ni una casuística que dictamine cómo proceder caso por caso o quién está facultado para hacerlo, los probables candidatos a integrar la lista de acciones, disposiciones, rasgos del carácter, pensamientos o motivaciones que podrían hacerse pasibles de un reproche moral a menudo será tan incierta que uno comenzará a preguntarse si el reproche, en estos ámbitos, puede que todavía tenga algún sentido ${ }^{62}$.

${ }^{60}$ Cf. supra, sec. 2

${ }^{61}$ Williams, B., "Internal Reasons and the Obscurity of Blame", en Making Sense of Humanity and Other Philosophical Papers, Cambridge University Press, Cambridge, 1995, pág. 40.

${ }^{62}$ Íbídem, págs. 43-44, asimismo Scanlon, T., Moral Dimensions: Permissibility, Meaning, Blame, Cambridge, Harvard University Press, 2008. 
Matías Parmigiani

Conforme el esquema heredado de la teoría general del delito, en cambio, sabemos que no habrá reproche penal a menos que haya una acción típica y antijurídica, con lo cual ya se abre ante nosotros un primer gran paraguas protector. El otro gran paraguas, por su parte, es el que se desprende del modo como Peralta (aunque no solo él) concibe la tarea de la dogmática, a la cual se le exige que entienda los elementos del delito "predominantemente como garantías del individuo frente al Estado", sin que esto implique hacer de ella, por supuesto, un "instrumento destinado a obstaculizar, en lo posible, la actividad punitiva estatal"63.

Es recién luego de sentirse amparado en la protección que le brindan ambos paraguas que Peralta adquiere la confianza para encarar su notable propuesta interpretativa en torno a las motivaciones reprochables. Como se observó, el objetivo de máxima consiste en dotar a la dogmática penal de un formato que también le permita mostrarse liberal en el tratamiento que le otorga a las motivaciones en general. Y es que, en la perspectiva de un análisis estrictamente liberal de la culpabilidad, el cual procura brindar un manto de protección especial a los derechos individuales, los motivos solo podrían tener relevancia en la medida en que significaran una disminución de la misma, no su agravamiento ${ }^{64}$.

¿Cómo conciliar entonces esta perspectiva con lo sindicado por los ordenamientos jurídicos que agravan la situación de un autor por la concurrencia de las motivaciones que podrían invadirlo? Básicamente, interpretando estas motivaciones no como motivaciones propiamente dichas, sino como indicadores de la ausencia de causales de justificación. Claro, si esta propuesta se aceptara, ella permitiría salvaguardar la intuición de que el Estado, después de todo, no debe castigar a las personas por lo que ocurre en el plano interno de su agencia. Sin embargo, aunque este resultado se recibiera con beneplácito, el gran

${ }^{63}$ Peralta, J. M., Motivos reprochables. Una investigación acerca de la relevancia de las motivaciones individuales para el Derecho penal liberal, Madrid, Marcial Pons, 2012, pág. 127. ${ }^{64}$ Cf. supra, sec. 2. 
problema que todavía persistiría entre nosotros es que seguiríamos sin ser capaces de entender no ya cómo podría operar el Estado en materia de penas (es decir, si agravándolas o disminuyéndolas) sino, como antes se dijo, en materia de reproches.

El resultado se vuelve especialmente curioso tras constatar que habría sido el propio Peralta quien comenzó a preparar el terreno para que la idea de pena pudiera ser separada de la idea de reproche, con todo lo que de esta separación se deriva. Conceptualmente, semejante separación no solo nos permite llegar a comprender por qué escenarios en los que penamos sin reprochar y/o reprochamos sin infligir pena alguna son mucho menos que meras posibilidades lógicas ${ }^{65}$; asimismo nos permite explicar, por un lado, que lo que sea que pretendamos reprocharle a alguien (un carácter, una creencia o una motivación), rara vez alcancemos a lograrlo exclusivamente por medio de la pena; y, por el otro, que como sea que penemos a alguien -esto es, más allá de la modalidad penal específica que adoptemos (si prisión efectiva, pago de multas, compensación a la víctima o lo que fuera)-, esa modalidad rara vez alcance a expresar lo que realmente pensamos o sentimos sobre su persona.

Como se echa de ver naturalmente, la posibilidad de concebir escenarios complementarios como estos de ninguna manera trae aparejada una determinada concepción del poder punitivo del Estado. En este sentido, no solo debe remarcarse que ninguna consecuencia de ese calibre se sigue en lo concerniente a cómo fijar los límites que el Estado tendría vedado transgredir so pena de incurrir en prácticas antiliberales. En rigor, tampoco ninguna consecuencia semejante se desprende en lo que atañe a las motivaciones individuales que suelen

${ }^{65}$ Peralta, J. M., Motivos reprochables. Una investigación acerca de la relevancia de las motivaciones individuales para el Derecho penal liberal, Madrid, Marcial Pons, 2012, pág. 111; Scanlon, T., Moral Dimensions: Permissibility, Meaning, Blame, Cambridge, Harvard University Press, 2008; Parmigiani, M., "Liberalismo, sanción y reproche: Una revisión crítica del concepto de reproche en la teoría jurídico-penal de C. S. Nino" [de próxima aparición en Isonomía. Revista de Teoría y Filosofia del Derecho (N. ${ }^{\circ}$ 39)], 2013. 
Matías Parmigiani

acompañar a los seres humanos, sea que se traduzcan o no en verdaderas acciones delictivas.

Tal cual lo ponen de manifiesto las últimas consideraciones, el hecho de que sea encarcelando a alguien durante $x$ cantidad de años el modo eminente como pretendemos comunicarle que ha sido guiado por una motivación -por ejemplo, la codicia- que merece mayor reprobación que otra -por ejemplo, el apremio económico- que solo le hubiera acarreado una pena de prisión de $x-n$ cantidad de años, no significa que sea exclusivamente por medio de esta pena que podamos expresar nuestra reprobación. Es más, si la pena y el reproche son dos conceptos distintos y separables, a los efectos de comunicar esa reprobación ni siquiera será necesario que una motivación merezca mayor pena que otra. Dos delitos del mismo tipo cometidos por motivaciones distintas bien puede que requieran penas del mismo calibre (i.e., penas cuantitativamente equivalentes), aun si no, como se imaginará, idénticos juicios de reproche.

\section{Bibliografía}

Al-Hakim, M., "Making Room for Hate Crime Legislation in Liberal Societies", en Criminal Law and Philosophy, 4 (3), 2010, págs. 341-358.

Farrell, M. D., El derecho liberal, Abeledo Perrot, Buenos Aires, 1998. Ferrajoli, L., Derecho y razón. Teoría del garantismo penal, Madrid, Trotta, 2001.

Feyerabend, Paul, "Realism and Instrumentalism: Comments on the Logic of Factual Support", en Realism, Rationalism and Scientific Method. Philosophical Papers, Vol. 1. Cambridge University Press, Cambridge, 1981, págs. 176-202.

Fricker, Miranda, "What's the Point of Blame?" (Draft), en http:// www.ucl.ac.uk/laws/jurisprudence/docs/2013/fricker_2013.pdf, 2013.

Hart, H. L. A., Obligación jurídica y obligación moral, traducción de Javier Esquivel y L. Alfonso Ortiz. Cuadernos de Crítica N. ${ }^{\circ}$ 3, México, 1977. 
Hume, D., Tratado de la naturaleza humana, 2. ${ }^{\text {a }}$ edición en español, trad. Félix Duque. Madrid, Tecnos, 1992.

Jackson, F. y Pettit, P., "Functionalism and Broad Content", en Jackson, F., Pettit, P. y Smith, M. (autores), Mind, Morality and Explanation (Selected Collaborations). Oxford University Press, Oxford, 2004, págs. 95-118.

Kant, I., Metafisica de las costumbres, traducción de Adela Cortina y Jesús Conill Sancho, Altaya-Tecno, Madrid, 1997.

Laudan, L., "Realism without the Real", en Philosophy of Science, 51, 1. (Mar.), 1984, págs. 156-162.

Lazos, E., "Autoconocimiento: una idea tensa", en Diánoia, vol. LIII, número 6, 2008, págs. 169-188.

Maxwell, G., "El estatus ontológico de las entidades teóricas", en Olivé Morett, L. R. y Pérez Ransanz, A. R., Filosofia de la ciencia: teoría y observación. UNAM: Siglo XXI Editores, 1989, págs. 116-144.

Mill, J.S., Ensayo sobre la libertad, traducción de M. A. Lavilla Navarro, Mestas Ediciones, Madrid, 2006.

Moran, R., Authority and Estrangement. An Essay on Self-Knowledge, Princeton University Press, Princeton, 2001.

Nino, C. S., Introducción a la filosofia de la acción humana, Buenos Aires, EUDEBA, 1987.

Parmigiani, M., "Liberalismo, sanción y reproche: Una revisión crítica del concepto de reproche en la teoría jurídico-penal de C. S. Nino" [de próxima aparición en Isonomía. Revista de Teoría y Filosofia del Derecho (N. ${ }^{\circ}$ 39)], 2013.

Peralta, J. M., Motivos reprochables. Una investigación acerca de la relevancia de las motivaciones individuales para el Derecho penal liberal, Madrid, Marcial Pons, 2012.

Putnam, H., "The Meaning of 'Meaning", en Mind, Language and Reality. Philosophical Papers, Vol. 2, Cambridge University Press, Cambridge, 1975, págs. 215-271.

Scanlon, T., Moral Dimensions: Permissibility, Meaning, Blame, Cambridge, Harvard University Press, 2008. 
Matías Parmigiani

Sellars, W., Ciencia, percepción y realidad, traducción de V. Sánchez de Zavala. Tecnos, Madrid, 1971.

Sher, G., "Blame for Traits", en Noûs 35:1, 2001, págs. 146-161.

Von Wright, G. H., Sobre la libertad humana, traducción de Amparo Gómez. Paidós, Barcelona, 2002.

Wall, S., Liberalism, Perfectionism and Restraint, Cambridge University Press, Cambridge, 1998.

Wiggins, D., "Deliberation and Practical Reason", en Needs, Values, Truth, Oxford University Press, Oxford, 1998, págs. 215-238.

Wittgenstein, L., Zettel, Basil Blackwell, Londres, 1967.

Williams, B., "Internal Reasons and the Obscurity of Blame", en Making Sense of Humanity and Other Philosophical Papers, Cambridge University Press, Cambridge, 1995, págs. 35-45.

, Verdad y veracidad, trad. Alberto Enrique Álvarez y Rocío Orsi. Tusquets Editores, Barcelona, 2006. 